\title{
VOLUME DO RECIPIENTE, ADUBAÇÃO E SUA FORMA DE MISTURA AO SUBSTRATO NO CRESCIMENTO INICIAL DE Peltophorum dubium (Sprengel) TAUBERT EM VIVEIRO ${ }^{1}$
}

\author{
Elizeu Luiz Brachtvogel² e Ubirajara Contro Malavasi ${ }^{3}$
}

\begin{abstract}
RESUMO - O ensaio comparou três volumes de recipientes, três tipos de adubação e duas formas de mistura do fertilizante ao substrato, no crescimento inicial de plântulas de Peltophorum dubium (Sprengel) Taubert (canafístula) em viveiro, num esquema fatorial 3 x 3 × 2 . Foram utilizados tubetes de 100 e $180 \mathrm{~cm}^{3}$ preenchidos com substrato comercial e sacos plásticos de 10 x $15 \mathrm{~cm}$ cheios com mistura de solo e vermiculita em partes iguais, fertilizados com fertilizante de liberação lenta (FLL) nas dosagens de 1,75 e 3,5 $\mathrm{kg} \mathrm{m}^{-3}$ e com formulação NPK a $1,0 \mathrm{~kg} \mathrm{~m}^{-3}$ de substrato. As formas de misturas adotadas foram aquelas com base por metro cúbico de substrato ou individualmente para cada recipiente. Na análise destrutiva realizada 12 semanas após a emergência, avaliaram-se o número de folhas, a altura da planta, o diâmetro do coleto e as massas secas da parte aérea, o sistema radicular e o total. Os resultados indicaram que a redução no volume do recipiente causou diminuição na massa seca, diâmetro e altura. O número de folhas, a massa seca da parte aérea e a massa seca total foram semelhantes nas plântulas sob fertilização com NPK, independentemente do volume do recipiente, o que não ocorreu naquelas sob FLL, onde esse parâmetro diminuiu com o volume do recipiente. O cálculo do índice de Dickson após 12 semanas indicou valores superiores em mudas com a forma de mistura convencional em relação à individual e maior naquelas sob fertilização com NPK, em comparação com as sob FLL.
\end{abstract}

Palavras-chave: Volume de recipiente, Fertilizante de liberação lenta e Mudas florestais.

\section{CONTAINER VOLUME, FERTILIZATION AND WAY TO MIX SUBSTRATE ON THE INITIAL GROWTH OF Peltophorum dubium (Sprengel) TAUBERT IN NURSERY}

\begin{abstract}
This essay compared three container volumes, conventional fertilizer, recommended and half recommended slow release fertilizer, and the way of mixing fertilizer in the substrate on the initial growth of Peltophorum dubium seedlings in a nursery. The statistical design was a randomized factorial $3 \times 3 \times 2$, using 180 and $100 \mathrm{~cm}^{3}$ plugs for containers filled with commercial substrate and plastic bags of $10 \times 15$ $\mathrm{cm}$ filled with soil and vermiculita in equal parts. For fertilization, a slow release fertilizer (FLL) was tested in the dosages of 3.5 and $1.75 \mathrm{~kg} \mathrm{~m}^{-3}$, as well as NPK in $1.0 \mathrm{~kg} \mathrm{~m}^{-3}$ of substrate. The adopted mixture form was based on a cubical substrate volume or individually for each container. A destructive analysis was done 12 weeks after emergence, evaluating leaf number, plant height, stem diameter, aerial, radicular system and total dry matter. The results indicated that, during the nursery phase, the reduction of container volume caused a reduction in dry matter, diameter and height. The leaf number, aerial and total dry matter was similar in seedlings under fertilization with NPK independent of container volume, which did not occur in those under $F L L$, where this parameter decreased with container volume. The calculated Dickson Index indicated superior values in seedlings with the conventional mixture form in relation to the individual one, and the biggest one in those under fertilization with NPK compared to the ones under FLL.
\end{abstract}

Keywords: Container volume, Slow release fertilizer and Forest seedlings.

\footnotetext{
${ }^{1}$ Recebido em 09.05.2008 e aceito para publicação em 14.10.2009.

${ }^{2}$ Universidade Estadual Paulista Júlio de Mesquita Filho, UNESP, Brasil. E-mail: <elizeub@fca.unesp.br>.

${ }^{3}$ Universidade Estadual do Oeste do Paraná, UNIOESTE, Brasil. E-mail: <umala@unioeste.br>.
} 


\section{INTRODUÇÃO}

O plantio de espécies florestais nativas, para fins de produção ou conservação, depende em grande parte da utilização de mudas produzidas em recipientes (CARNEIRO, 1995). As dimensões dos recipientes devem adequar-se às características das espécies (GOMES et al., 1990). Com crescimento inicial lento, algumas espécies florestais nativas necessitam de mais tempo no viveiro para alcançar tamanho mínimo exigível, que por sua vez induz o uso de recipientes de maior tamanho (CARNEIRO, 1995).

A produção de mudas de espécies florestais em recipientes deve ser preferida quando inexistem limitações financeiras para aquisição dos recipientes, as práticas de viveiros são mecanizadas (DAVIDE, 1995) e o crescimento vegetal é suficientemente plástico para tolerar as limitações impostas pelos recipientes (CARNEIRO, 1995). Entretanto, um dos problemas detectados nas mudas produzidas em recipientes de paredes rígidas e de pequeno volume são as deformações radiculares, acentuadas pelo menor volume de substrato que aqueles comportam. Essas deformações tendem a continuar após a fase de viveiro, destacando-se a importância de priorizar metodologias de produção de mudas que não provoquem deformações em suas raízes. Parviainen e Tervo (1989) - estudando espécies do gênero Pinus e Barroso et al. (2000a) e Freitas et al. (2005) - estudando espécies de Eucalyptus observaram a persistência das deformações radiculares após a retirada dos recipientes.

Segundo Pezzutti et al. (1999), o conhecimento do crescimento das plantas no viveiro, em resposta a fatores como água, luz, temperatura, fertilizantes e restrição radicular, reveste-se de importância para produzir mudas de qualidade, em quantidade suficiente e a custo menor. Mudas aptas ao plantio no campo devem ser sadias e possuir resistência a estresses que lhe permitam sobreviver às condições adversas do meio (GOMES et al., 1996).

Embora sendo sistemas eficientes, a produção de mudas em ambiente protegido requer a utilização de recipientes com dimensões limitadas, e o longo período de permanência dessas plantas nesses recipientes torna o sistema radicular sujeito a restrições físicas (REZENDE et al., 2002), tornando também os substratos suscetíveis a perdas de nutrientes por lixiviação, sendo a adubação fator decisivo para o bom desenvolvimento das mudas (PERIN et al., 1999).
Em virtude disso, a adubação, hoje fundamentada em fertilizantes solúveis, apresenta empecilhos que reduzem sua eficácia. Entre eles, destacam-se os custos de aplicação dos fertilizantes solúveis e a baixa eficiência da adubação nitrogenada, que em certas condições podem ser inferiores a 50\% (MATTOS JUNIOR et al., 2002).

Geralmente, os fertilizantes podem ser solúveis ou pouco solúveis (liberação lenta), porém não encapsulados. Os fertilizantes de liberação controlada ou liberação lenta (FLL), encapsulados ou revestidos com resina (YAGUE, 1994; TRENKEL, 1997), ainda são pouco utilizados no Brasil (MORAES NETO et al., 2003b).

Os FLL, em geral, produzem maior crescimento das plantas e menos lixiviação que os mesmos fertilizantes não encapsulados (COLE e DOLE, 1997). A perda de nutrientes por lixiviação aumenta com o maior volume de substrato, bem como a menor capacidade de retenção de água e CTC deste (HUETT e MORRIS, 1999).

É necessário, contudo, conhecer o comportamento das espécies quanto à rapidez de crescimento, porque em geral aquelas da categoria sucessional das pioneiras têm ciclo de produção mais curto que o das espécies de sucessão mais tardia, e, se for aplicado um FLL de tempo de duração de 3-4 meses, ele pode ter pouco efeito sobre as últimas (MORAES NETO et al., 2003a). No entanto, a lixiviação de nitrogênio em FLL pode ser superior a aplicações frequentes e pequenas de fertilizantes solúveis em água (COX, 1993).

Dessa forma, o objetivo do ensaio foi comparar o crescimento inicial de mudas de Peltophorum dubium (Sprengel) Taubert (Caesalpinioideae) conduzidas sob condições de viveiro em função da fertilização convencional e de liberação lenta, bem como a forma de mistura do fertilizante ao substrato, em recipientes de três volumes distintos.

\section{MATERIAL E MÉTODOS}

O ensaio foi instalado e conduzido em casa de vegetação no Campus da Unioeste de Marechal Cândido Rondon, PR, localizado a $24^{\circ} 33^{\prime \prime} 30^{\prime}$ S e $54^{\circ} 02^{\prime \prime} 44^{\prime}$ $\mathrm{W}$, com altitude de $420 \mathrm{~m}$, temperaturas médias de 14 ${ }^{\circ} \mathrm{C}$ na época mais fria e $28{ }^{\circ} \mathrm{C}$ na época mais quente, de outubro a julho. O clima local é do tipo Cfa (Köppen) e a precipitação média anual, 1804 mm.

O delineamento experimental utilizado foi um fatorial $3 \times 3 \times 2$, constituído de três recipientes, três níveis de adubação e duas formas de mistura do fertilizante 
ao substrato, em 10 repetições para cada combinação. Os recipientes testados foram dois tubetes plásticos de seção circular, volume de 100 e 180 cm ${ }^{3}$ e saco plástico convencional de $10 \mathrm{~cm}$ de diâmetro por $15 \mathrm{~cm}$ de altura. Os níveis de adubação utilizados foram a composta por NPK e micronutrientes (15-70-10 + fritas), conforme descrito por Gonçalvez (2000), com a dose de 1,0 kg $\mathrm{m}^{-3}$ de substrato (NPK), a metade $\left(1,75 \mathrm{~kg} \mathrm{~m}^{-3}\right)$ e a recomendação-padrão $\left(3,5 \mathrm{~kg} \mathrm{~m}^{-3}\right)$ de um fertilizante de liberação lenta (FLL) (Basacote ${ }^{\circledR}$ Plus 3M 16-8-12 $(+2+5)+$ micronutrientes), recomendação essa feita pelo fabricante do fertilizante. As formas de mistura do fertilizante ao substrato foram a convencional com base no volume do substrato e a com base no volume do recipiente, individualmente.

Sementes de Peltophorum dubium (Sprengel) Taubert foram submetidas à quebra de dormência por água aquecida a $80^{\circ} \mathrm{C}$ e pré-germinadas em Gearbox (sobre papel) em germinador à temperatura constante de $25^{\circ} \mathrm{C}$, para uniformizar a germinação. Somente sementes que exibiam pelo menos $2 \mathrm{~mm}$ de radícula foram utilizados para semeadura. Os tubetes foram preenchidos com substrato comercial (Plantmax ${ }^{\circledR}$ ) para essências florestais e o saco plástico, por uma mistura de solo Lvef (EMBRAPA, 1999) e vermiculita, em partes volumétricas iguais. As adubações estudadas foram misturadas ao substrato de forma convencional em betoneira, com base no volume do substrato e, individualmente, com o auxílio de saco plástico, promovendo a completa homogeneização. Irrigações até a saturação foram promovidas a cada dois dias, enquanto nas adubações de cobertura se utilizaram os critérios descritos por Gonçalvez (2000).

Após a semeadura, realizada em setembro de 2005, as mudas nas quais o recipiente era o saco plástico permaneceram sob bancada, com periódica mudança de lugar para evitar a emissão de raízes para fora da embalagem, e as em tubetes suspensas em telado, de modo a promover a poda das raízes pelo ar. O ensaio foi encerrado 12 semanas após a emergência com o aparecimento de raízes no fundo dos tubetes de menor volume $\left(100 \mathrm{~cm}^{3}\right)$, quando se procedeu à análise destrutiva das mudas para coleta dos dados. As variáveis mensuradas foram número de folhas (NF), altura da planta $(\mathrm{cm})(\mathrm{H})$, diâmetro do coleto (mm) (D), massas secas da parte aérea (MSPA), sistema radicular (MSSR) e total (MST) (g), assim como o índice de Dickson, utilizado como indicador da qualidade das mudas (DICKSON et al., 1960). Na determinação da massa seca, utilizaram-se estufa de circulação de ar forçada a $65^{\circ} \mathrm{C}$ até massa constante e balança analítica de precisão de $0,0001 \mathrm{~g}$.

\section{RESULTADOS}

Ao final de 12 semanas após a emergência, a análise de variância indicou que os fatores testados influenciaram as variáveis analisadas, conforme demonstrado na Tabela 1.

Tabela 1 - Quadrados médios de altura (H), diâmetro do coleto (D), número de folhas (NF), massa seca da parte aérea (MSPA), massa seca do sistema radicular (MSSR) e massa total (MST) de mudas de Peltophorum dubium 12 semanas após a emergência em casa de vegetação. Marechal Cândido Rondon, 2006.

Table 1 - Medium squares of height (H), stem diameter (D), leaf number (NF), aerial dry matter (MSPA), radicular system dry matter (MSSR), total dry matter (MST) for Peltophorum dubium seedlings 12 weeks after emergence growing in a greenhouse. Marechal Cândido Rondon, 2006.

\begin{tabular}{|c|c|c|c|c|c|c|c|}
\hline \multirow[t]{2}{*}{$\overline{\mathrm{CV}}$} & \multirow[t]{2}{*}{ GL } & \multicolumn{6}{|c|}{ Quadrados médios } \\
\hline & & $\mathrm{H}$ & $\mathrm{D}$ & $\mathrm{NF}$ & MSPA & MSSR & MST \\
\hline Mistura (A) & 1 & $332,929 * *$ & $0,7254 *$ & $1,1111 \mathrm{NS}$ & $0,0518 \mathrm{NS}$ & $0,3086 * *$ & $0,6134 * *$ \\
\hline Recipiente (B) & 2 & $561,3363 * *$ & $11,3849 * *$ & $17,6444 * *$ & $15,8785 * *$ & $1,2058 * *$ & $25,8034 \mathrm{NS}$ \\
\hline Adubação (C) & 2 & $213,0963 * *$ & $0,1618 \mathrm{NS}$ & $0,8444 \mathrm{NS}$ & $1,5119 * *$ & $0,180 \mathrm{NS}$ & $1,2949 \mathrm{NS}$ \\
\hline$A \times B$ & 2 & $203,5343 * *$ & $2,3733 * *$ & $7,7111 * *$ & $0,6479 \mathrm{NS}$ & $0,5448 * *$ & $2,3809 * *$ \\
\hline$A \times C$ & 2 & $137,019 * *$ & $0,0003 \mathrm{NS}$ & $0,3111 \mathrm{NS}$ & 0,2920 NS & $0,0098 \mathrm{NS}$ & $0,2105 \mathrm{NS}$ \\
\hline$B \times C$ & 4 & $301,9447 * *$ & $0,5875^{*}$ & $2,2444^{*}$ & $1,9968 * *$ & $0,0502 \mathrm{NS}$ & $2,1306 * *$ \\
\hline$A \times B \times C$ & 4 & $30,4863 \mathrm{NS}$ & $0,1176 \mathrm{NS}$ & $1,7111 \mathrm{NS}$ & 0,2799 NS & $0,0597 \mathrm{NS}$ & $0,3187 \mathrm{NS}$ \\
\hline (tratamentos) & 17 & 3892,6250 & 1,8463 & 4,2327 & 2,6953 & 0,2532 & 4,1053 \\
\hline Resíduo & 162 & 1906,8560 & 0,1676 & 0,8778 & 0,3042 & 0,0252 & 0,4697 \\
\hline Média & & 28,1767 & 3,4111 & 6,8222 & 1,2460 & 0,2860 & 1,5446 \\
\hline Desv. Pad. & & 5,1463 & 0,4094 & 0,9369 & 0,5516 & 0,1587 & 0,6854 \\
\hline C.V. & & 18,2643 & 12,0029 & 13,733 & 44,2674 & 53,1505 & 44,3739 \\
\hline
\end{tabular}

** $\mathrm{e}^{*}$ : significativos pelo teste $\mathrm{F}$, respectivamente, para $\alpha \leq 0,01$ e 0,05 . NS: Não significativo.

** and * : significant in F test respectively for $\alpha \leq 0.01$ e 0.05 . NS: Not significant.

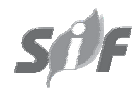

R. Árvore, Viçosa-MG, v.34, n.2, p.223-232, 2010 
O fator forma de mistura do fertilizante ao substrato (A) influenciou as variáveis altura de muda $(\mathrm{H})$, diâmetro do coleto (D) e massa seca do sistema radicular (MSSR), bem como a massa seca total (MST). O fator recipiente (B) influenciou todas as variáveis mensuradas, exceto a MST. O fator adubação (C) influenciou H e a massa seca da parte aérea (MSPA).

Com relação às interações, observou-se que A x $\mathrm{B}$ foi significativa em todas as variáveis analisadas, exceto a MSPA; e A x C ocorreu significativamente apenas em $\mathrm{H}$ e B x C em todas as variáveis analisadas, exceto MSSR. Não foram observadas interações significativas do tipo A x B x C nesse ensaio.

Pelos dados descritos na Tabela 2, observa-se que as mudas de Peltophorum dubium conduzidas em saco plástico apresentaram valores médios significativamente maiores de altura quando a mistura foi feita de forma convencional, mas não quando realizada de forma individual para cada recipiente $(p>0,05)$. Quando foram comparadas as formas de mistura dentro de cada adubação, verificou-se incremento na altura apenas nas mudas provenientes da maior dose de FLL. Na forma de mistura convencional, as duas adubações com FLL foram superiores ao NPK, e na individual não ocorreu diferença entre as adubações $(\mathrm{p}>0,05)$.

Quando foi comparado o efeito da adubação nos recipientes, observou-se que a maior altura de muda obtida no saco plástico foi com o uso de recomendaçãopadrão de FLL e metade desta - maiores que a fertilização com NPK. A altura da muda no recipiente de $180 \mathrm{~cm}^{3}$ foi menor com o uso de adubação convencional, em comparação com a menor dose de FLL e semelhante à maior dose desta. Não houve diferença significativa $(p>0,05)$ nas diferentes adubações testadas no tubete de $100 \mathrm{~cm}^{3}$ (Tabela 3).

Observou-se redução na diferença de altura das mudas com e sem o uso de FLL com a diminuição do volume do recipiente. No saco plástico, o recipiente

Tabela 2-Medias de altura de mudas (H) (cm), diâmetro do coleto (D) (mm), número de folhas (NFO), massa seca do sistema radicular (MSSR) e massa seca total (MST) (g) na interação recipiente x formas de mistura testadas e médias de altura de mudas $(\mathrm{H})(\mathrm{cm})$ na interação formas de mistura $\mathrm{x}$ adubação para mudas de Peltophorum dubium 12 semanas após a emergência em casa de vegetação. Marechal Cândido Rondon, 2006.

Table 2 - Mean height of seedlings $(H)(\mathrm{cm})$, stem diameter $(D)(\mathrm{mm})$, leaf number (NFO), radicular system dry matter (MSSR) and total dry matter (MST) $(g)$ in the Container volume $x$ Way of mixing interaction and means of height seedlings $(\mathrm{H})(\mathrm{cm})$ in the Way of mixing $x$ fertilizer interaction for Peltophorum dubium seedlings 12 weeks after emergence growing in a greenhouse. Marechal Cândido Rondon, 2006.

\begin{tabular}{|c|c|c|c|c|}
\hline \multirow[t]{2}{*}{ Variável } & \multirow[t]{2}{*}{ Forma de mistura } & \multicolumn{3}{|c|}{ Recipiente } \\
\hline & & $180 \mathrm{~cm}^{3}$ & $100 \mathrm{~cm}^{3}$ & Saco plástico \\
\hline \multirow[t]{2}{*}{$\overline{\mathrm{H}^{(1)}}$} & Convencional & 26,7400 а B & 25,5200 а B & 38,0400 a $\mathrm{A}$ \\
\hline & Individual & 26,0333 а $A$ & 24,5467 a $A$ & $28,1800 \mathrm{~b} \mathrm{~A}$ \\
\hline \multirow[t]{2}{*}{$\mathrm{D}^{(2)}$} & Convencional & 3,0553 b B & 2,8407 a $B$ & 3,7133 b A \\
\hline & Individual & 3,4100 a $B$ & 2,9673 a $\mathrm{C}$ & 4,4800 a $A$ \\
\hline \multirow[t]{2}{*}{$\mathrm{NFO}^{(2)}$} & Convencional & $6,4000 \mathrm{~b} \mathrm{AB}$ & 5,8667 а B & 7,0667 b A \\
\hline & Individual & 7,2000 а $B$ & 6,2667 a $\mathrm{C}$ & 8,1333 а $A$ \\
\hline \multirow[t]{2}{*}{$\operatorname{MSSR}^{(2)}$} & Convencional & 0,1773 b B & 0,0953 a $C$ & 0,3187 b A \\
\hline & Individual & 0,3060 a $\mathrm{B}$ & 0,1700 a $\mathrm{C}$ & 0,7240 a $A$ \\
\hline \multirow[t]{2}{*}{$\operatorname{MST}^{(1)}$} & Convencional & 1,0367 а $\mathrm{B}$ & 0,7887 a $\mathrm{B}$ & 2,2093 b A \\
\hline & Individual & 1,3880 а $\mathrm{B}$ & 0,8693 а $\mathrm{B}$ & 2,9753 a $\mathrm{A}$ \\
\hline \multirow[t]{2}{*}{ Variável } & Forma de mistura & \multicolumn{3}{|c|}{ Adubação } \\
\hline & & $3,5 \mathrm{Kg} \mathrm{m}^{-3} \mathrm{FLL}$ & $1,75 \mathrm{Kg} \mathrm{m}^{-3} \mathrm{FLL}$ & NPK \\
\hline \multirow[t]{2}{*}{$\mathrm{H}^{(1)}$} & Convencional & 33,6000 a $\mathrm{A}$ & 31,7467 a $\mathrm{A}$ & 24,9533 а $B$ \\
\hline & Individual & 25,3733 b A & 28,1200 а $A$ & 25,2667 а $A$ \\
\hline
\end{tabular}

(1) Médias seguidas de letras diferentes verticalmente (minúsculas) e horizontalmente (maiúsculas) diferem estatisticamente a $1 \%$ de probabilidade. ${ }^{(2)}$ Médias seguidas da mesma letra minúscula na vertical e maiúscula na horizontal não diferem estatisticamente a $5 \%$ de probabilidade, para tubete de $180 \mathrm{~cm}^{3}$ na vertical e $1 \%$ para os demais.

(1) Means followed by different letters vertically (minuscule) and horizontally (majuscules) differed statistically in $1 \%$ probability. (2) Means followed by the same letters vertically (minuscule) and horizontally (majuscules) did not differ statistically in $5 \%$ probability for $180 \mathrm{~cm}^{3}$ plugs in the vertical and $1 \%$ for others.

R. Árvore, Viçosa-MG, v.34, n.2, p.223-232, 2010 
Tabela 3 - Medias de altura de mudas (H) (cm), diâmetro do coleto (D) (mm), número de folhas (NFO), massa seca da parte aérea (MSPA) e massa seca total (MST) (g) na interação recipiente x adubação de mudas de Peltophorum dubium 12 semanas após a emergência em casa de vegetação. Marechal Cândido Rondon, 2006.

Table 3 - Means of height seedlings $(H)(\mathrm{cm})$, stem diameter $(D)(\mathrm{mm})$, leaf number $(\mathrm{NFO})$, aerial dry matter (MSPA) and total dry matter (MST) $(g)$ in the Container volume x Fertilizer interaction for Peltophorum dubium seedlings 12 weeks after emergence growing in a greenhouse. Marechal Cândido Rondon, 2006.

\begin{tabular}{|c|c|c|c|c|}
\hline \multirow[t]{2}{*}{ Variável } & \multirow[t]{2}{*}{ Adubação } & \multicolumn{3}{|c|}{ Recipiente } \\
\hline & & $180 \mathrm{~cm}^{3}$ & $100 \mathrm{~cm}^{3}$ & Saco plástico \\
\hline \multirow[t]{3}{*}{$\mathrm{H}^{(1)}$} & $3,5 \mathrm{Kg} \mathrm{m}^{-3} \mathrm{FLL}$ & 27,4800 ab B & 26,0000 а B & 39,5400 a A \\
\hline & $1,75 \mathrm{Kg} \mathrm{m}^{-3} \mathrm{FLL}$ & 28,7600 а $\mathrm{B}$ & 24,7800 а $\mathrm{B}$ & 36,2600 a $A$ \\
\hline & NPK & $22,9200 \mathrm{~b} \mathrm{~A}$ & 24,3200 а $A$ & $23,5300 \mathrm{~b} \mathrm{~A}$ \\
\hline \multirow[t]{3}{*}{$\mathrm{D}^{(2)}$} & 3,5 $\mathrm{Kg} \mathrm{m}^{-3} \mathrm{FLL}$ & 3,4150 а $\mathrm{B}$ & 2,9210 а B & 4,2530 a $\mathrm{A}$ \\
\hline & $1,75 \mathrm{Kg} \mathrm{m}^{-3} \mathrm{FLL}$ & 3,4010 а $\mathrm{B}$ & 2,9100 а C & 4,1690 a $\mathrm{A}$ \\
\hline & NPK & 2,8020 a $\mathrm{B}$ & 2,8810 a C & 3,8680 a $\mathrm{A}$ \\
\hline \multirow[t]{3}{*}{$\mathrm{NFO}^{(1)}$} & 3,5 $\mathrm{Kg} \mathrm{m}^{-3} \mathrm{FLL}$ & 6,2000 а $\mathrm{B}$ & 6,1000 а $B$ & 7,8000 a $\mathrm{A}$ \\
\hline & $1,75 \mathrm{Kg} \mathrm{m}^{-3} \mathrm{FLL}$ & 7,1000 а $\mathrm{B}$ & 5,7000 а $B$ & 7,6000 а $\mathrm{A}$ \\
\hline & NPK & 7,1000 а $\mathrm{A}$ & 6,4000 a $\mathrm{A}$ & 7,4000 а $\mathrm{A}$ \\
\hline \multirow[t]{3}{*}{$\operatorname{MSPA}^{(3)}$} & $3,5 \mathrm{Kg} \mathrm{m}^{-3} \mathrm{FLL}$ & 0,8460 а $\mathrm{B}$ & 0,7690 а $\mathrm{B}$ & 2,7220 a $\mathrm{A}$ \\
\hline & $1,75 \mathrm{Kg} \mathrm{m}^{-3} \mathrm{FLL}$ & 0,9870 а $\mathrm{B}$ & 0,6720 а B & 2,2090 a $\mathrm{A}$ \\
\hline & NPK & 1,0790 а $\mathrm{AB}$ & 0,6480 а $\mathrm{B}$ & $1,2820 \mathrm{~b} \mathrm{~A}$ \\
\hline \multirow[t]{3}{*}{$\operatorname{MST}^{(2)}$} & $3,5 \mathrm{Kg} \mathrm{m}^{-3} \mathrm{FLL}$ & 1,3630 а $\mathrm{B}$ & 0,9010 а B & 3,2980 a $\mathrm{A}$ \\
\hline & $1,75 \mathrm{Kg} \mathrm{m}^{-3} \mathrm{FLL}$ & 1,2490 а $\mathrm{B}$ & 0,8220 а $\mathrm{B}$ & 2,6240 a $\mathrm{A}$ \\
\hline & NPK & 1,0250 а $\mathrm{B}$ & 0,7640 а $\mathrm{B}$ & $1,8550 \mathrm{~b} \mathrm{~A}$ \\
\hline
\end{tabular}

(1) Médias seguidas da mesma letra minúscula na vertical e maiúscula na horizontal não diferem estatisticamente a 5\% de probabilidade, para tubete de $180 \mathrm{~cm}^{3}$ na vertical e $1 \%$ para os demais. ${ }^{(2)}$ Médias seguidas da mesma letra minúscula na vertical e maiúscula na horizontal não diferem estatisticamente a 1\% de probabilidade. (3) Médias seguidas da mesma letra minúscula na vertical e maiúscula na horizontal não diferem estatisticamente a 5\% de probabilidade, para médias de NPK (na horizontal) e $1 \%$ para as demais.

${ }^{(1)}$ Means followed by the same letters vertically (minuscule) and horizontally (majuscules) did not differ statistically in 5\% probability for $180 \mathrm{~cm}^{3}$ plugs in the vertical and $1 \%$ for others. ${ }^{(2)}$ Means followed by the same letters vertically (minuscule) and horizontally (majuscules) did not differ statistically in $1 \%$ probability. ${ }^{(3)}$ Means followed by the same letters vertically (minuscule) and horizontally (majuscules) did not differ statistically in 5\% probability for NPK means (horizontal) and $1 \%$ for others.

de maior volume, a diferença foi mais ampla com $\mathrm{p}<0,01$, reduzindo-se no tubete de $180 \mathrm{~cm}^{3}(\mathrm{p}<0,05)$ e não existindo no recipiente de menor tamanho (p > 0,05) (Tabela 3).

Similarmente à altura, o diâmetro do coleto nas plântulas de Peltophorum dubium conduzidas sob recipientes de maior dimensão apresentou maiores médias (Tabelas 2 e 3), tanto na forma convencional de mistura quanto na individual. Quando foram comparadas as formas de mistura em cada um dos recipientes (Tabela 2), verificou-se que a mistura individualizada da adubação promoveu aumento do diâmetro do coleto em relação à forma convencional de mistura. No recipiente de maior dimensão (saco plástico), a diferença foi maior ( $\mathrm{p}<0,01$ ), decrescendo no tubete de $180 \mathrm{~cm}^{3}(\mathrm{p}<0,05)$ e inexistindo no recipiente de menor tamanho $(\mathrm{p}>0,05)$.
Quando foi comparada a adubação dos diferentes recipientes no diâmetro das mudas, observou-se que sempre as maiores médias estavam na embalagem plástica, independentemente do tipo de adubação utilizada (Tabela 3). Quando se utilizaram a adubação convencional e a metade da recomendada de FLL, a embalagem menor obteve o menor diâmetro, porém, quando foi usada a recomendação-padrão de FLL, o diâmetro das plântulas foi inferior apenas em relação ao saco plástico, sendo semelhante ao tubete de $180 \mathrm{~cm}^{3}$.

Da mesma forma, o número de folhas no recipiente menor (tubete de $100 \mathrm{~cm}^{3}$ ) não foi influenciado pela forma de mistura, na interação A x B. Com o aumento do volume do recipiente (tubete de $180 \mathrm{~cm}^{3}$ e saco plástico), obteve-se maior número de folhas na forma de mistura individual (Tabela 2).

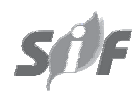

R. Árvore, Viçosa-MG, v.34, n.2, p.223-232, 2010 
Comparando o número de folhas médio dos tipos de adubação nos diferentes recipientes, observaram-se valores semelhantes, independentemente do recipiente. Com relação às médias de recipientes, obtiveram-se valores semelhantes naquelas com o uso de NPK, porém com o uso de FLL em dose recomendada ou a metade deste os valores de número de folhas foram maiores no saco plástico, em comparação com os demais recipientes ( $\mathrm{p}<0,01)$ (Tabela 3$)$.

Pelas médias de massa seca da parte aérea de recipiente em cada uma das adubações testadas, notou-se que no saco plástico houve maior acúmulo de massa seca na parte aérea, nas três formas de adubação estudadas (Tabela 3). Quando se utilizou a dose recomendada de FLL ou a metade desta, no saco plástico foram obtidas médias superiores às dos demais recipientes, diferentemente do observado no NPK, em que este foi superior apenas ao recipiente menor. Entretanto, quando foram comparadas as formas de adubação dentro dos diferentes recipientes testados, percebeu-se que nos dois recipientes menores não houve diferença significativa nas médias de adubação. Porém, quando em saco plástico, o uso de NPK resultou em menor massa seca da parte aérea, em comparação com as demais adubações.

A massa seca do sistema radicular foi afetada pelo volume do recipiente e forma de mistura utilizada (Tabela 2). Comparando as formas de mistura em cada recipiente, as maiores médias foram observadas em mudas provenientes de mistura do fertilizante individualizada nos dois maiores recipientes, sendo semelhantes no menor deles. Nas médias de forma de mistura nos diferentes recipientes, em ambas a massa seca do sistema radicular decresceu juntamente com o volume do recipiente.

Quanto à massa seca total para as formas de misturas em cada recipiente, as plântulas em saco plástico obtiveram maior matéria seca quando sob a forma de mistura individualizada, não diferindo nos demais. Quando foram comparadas as médias de recipientes de cada forma de mistura, verificou-se comportamento semelhante em ambas, em que no saco plástico as médias foram significativamente maiores (Tabela 2). Na interação de adubação e recipiente, quando foram comparadas as médias das adubações de cada recipiente, notou-se que ambas as adubações com FLL foram estatisticamente superiores à fertilização com NPK em saco plástico, não diferindo nos recipientes menores (Tabela 3). Na comparação dos recipientes de cada forma de mistura ou adubação, o saco plástico foi o recipiente de maior matéria seca em ambas as formas de mistura do fertilizante ao substrato e adubações testadas, estatisticamente superior aos demais, os quais não diferiram entre si.

Tabela 4 - Análise de variância do Índice de Dickson de mudas de Peltophorum dubium 12 semanas após a emergência em casa de vegetação. Marechal Cândido Rondon, 2006.

Table 4 - Dickson index variances analyzed for Peltophorum dubium seedlings 12 weeks after emergence growing in a greenhouse. Marechal Cândido Rondon, 2006.

\begin{tabular}{|c|c|c|c|c|}
\hline \multicolumn{5}{|c|}{ Análise de Variância } \\
\hline $\mathrm{CV}$ & GL & SQ & $\mathrm{QM}$ & $\mathrm{F}$ \\
\hline Mistura (A) & 1 & 0,0673 & 0,0673 & $15,5777 * *$ \\
\hline Recipiente (B) & 2 & 0,4577 & 0,2288 & $529378 * *$ \\
\hline Adubação (C) & 2 & 0,0032 & 0,0160 & $0,3674 \mathrm{NS}$ \\
\hline$A \times B$ & 2 & 0,2244 & 0,1122 & $25,9571 * *$ \\
\hline$A \times C$ & 2 & 0,0005 & 0,0002 & $0,0524 \mathrm{NS}$ \\
\hline$B \times C$ & 4 & 0,0202 & 0,0050 & $1,1658 \mathrm{NS}$ \\
\hline$A \times B \times C$ & 4 & 0,0102 & 0,0025 & $0,5891 \mathrm{NS}$ \\
\hline (tratamentos) & 17 & 0,7834 & 0,0461 & \\
\hline Resíduo & 162 & 0,3112 & 0,0043 & \\
\hline Média Geral & & 0,1273 & & \\
\hline Desv. Pad. & & 0,0657 & & \\
\hline C.V. & & 51,6537 & & \\
\hline
\end{tabular}

** : significativo pelo teste $\mathrm{F}(\alpha \leq 0,01)$. NS: Não significativo.

** : Significant for F test $(\alpha \leq 0.01)$. NS: Not significant.

R. Árvore, Viçosa-MG, v.34, n.2, p.223-232, 2010 
Tabela 5 - Médias do Índice de Dickson em mudas de Peltophorum dubium 12 semanas após a emergência em casa de vegetação na interação recipiente $\mathrm{x}$ forma de mistura do fertilizante ao substrato e nos efeitos de formas de mistura, adubação e recipiente testados. Marechal Cândido Rondon, 2006.

Table 5 - Dickson index means for Peltophorum dubium seedlings 12 weeks after emergence growing in a greenhouse in the Container volume $x$ Way of mixing interaction, and effects of Way of mixing, Fertilizer and Container volume. Marechal Cândido Rondon, 2006.

\begin{tabular}{|c|c|c|c|c|c|}
\hline & \multirow[t]{2}{*}{ Forma de mistura } & \multicolumn{3}{|c|}{ Recipiente } & \\
\hline & & $180 \mathrm{~cm}^{3}$ & $100 \mathrm{~cm}^{3}$ & Saco plástico & \\
\hline & Convencional & 0,1218 a $\mathrm{A}$ & 0,0475 a $\mathrm{B}$ & 0,3206 а A & \\
\hline & Individual & 0,0739 b B & 0,0695 а B & 0,1305 b A & \\
\hline Forma de mistura & Média & Adubação & Média & Recipiente & Média \\
\hline Convencional & 0,1546 a & $3,5 \mathrm{Kg} \mathrm{m}^{-3} \mathrm{FLL}$ & $\begin{array}{ll}0,0978 \quad \mathrm{~b} \\
\end{array}$ & $180 \mathrm{~cm}^{3}$ & $0,1278 \mathrm{a}$ \\
\hline Individual & $0,0999 \mathrm{~b}$ & $1,75 \mathrm{Kg} \mathrm{m}^{-3} \mathrm{FLL}$ & $0,0585 \quad b$ & $100 \mathrm{~cm}^{3}$ & $0,1198 \mathrm{a}$ \\
\hline- & - & NPK & 0,2255 a & Saco plástico & $0,1343 \mathrm{a}$ \\
\hline
\end{tabular}

Para a interação recipiente $\mathrm{x}$ forma de mistura, médias seguidas da mesma letra minúscula na vertical e maiúscula na horizontal não diferem estatisticamente a 5\% de probabilidade para médias de tubete de $180 \mathrm{~cm}^{3}$ na vertical e $1 \%$ para as demais. Para médias dos efeitos de formas de mistura, adubação e recipiente testados, médias seguidas da mesma letra na vertical não diferem estatisticamente a $1 \%$ de probabilidade.

For Container volume $x$ Way of mixing interaction, means followed by the same letters vertically (minuscule) and horizontally (majuscules) did not differ statistically in $5 \%$ probability for $180 \mathrm{~cm}^{3}$ plugs in the vertical and $1 \%$ for others. For effects of Way of mixing, Fertilizer and Container volume, means followed by the same letters in vertical did not differ statistically in $1 \%$ probability.

Os índices de qualidade das mudas ao final das 12 semanas após a emergência indicaram efeito na forma de mistura, volume de recipiente e interação entre esses (Tabela 4).

Pelos valores descritos na Tabela 5, observou-se que as médias do índice de qualidade de mudas nas formas de mistura nos recipientes testados foram maiores nas plantas sob a forma de mistura convencional, nos recipientes saco plástico e tubete de $180 \mathrm{~cm}^{3}$, não diferindo entre as formas no recipiente menor. Na forma de mistura convencional, observou-se a menor média do índice de qualidade de mudas no recipiente de menor volume $\left(100 \mathrm{~cm}^{3}\right)$, sendo os demais semelhantes. Na outra forma de mistura, o maior índice também correspondeu ao tratamento com saco plástico, com resultados semelhantes entre si nos outros recipientes e estatisticamente inferiores ao primeiro.

\section{DISCUSSÃO}

Com relação ao fato de as plântulas oriundas de tubetes de 100 e $180 \mathrm{~cm}^{3}$ terem alcançado os menores valores de altura quando se aplicaram a recomendaçãopadrão e a metade de FLL, resultados similares foram obtidos por Brissette (1990) com Pinus echinata e Gomes et al. (1990) com Pinus caribaea, Tabebuia serratifolia, Copaifera longsdorffii e Piptadenia peregrina, em que a redução do volume do recipiente causou menores plântulas. Já naquelas sob fertilização convencional (NPK), independentemente do recipiente utilizado, não houve diferença significativa ( $p>0,05)$ (Tabela 3). A maior solubilidade inicial dos adubos convencionais, se em excesso, pode ser prejudicial por causar deficiência nutricional subsequentemente (MATTOS JUNIOR et al., 2002). Nesse sentido, conforme se pôde observar na interação B x C, foi verificada redução na diferença de altura das mudas com e sem o uso de FLL, a qual ocorreu também com a diminuição do volume do recipiente, em cada adubação testada. No saco plástico, o recipiente de maior volume, a diferença foi mais ampla, com $\mathrm{p}<0,01$, reduzindo-se no tubete de $180 \mathrm{~cm}^{3}$ $(p<0,05)$ e não existindo no recipiente de menor tamanho ( $>$ > 05) (Tabela 3). Porém, quando o fertilizante foi misturado individualmente, não houve diferença significativa entre os recipientes, conforme demonstrado na Tabela 2.

A altura da muda foi considerada um dos parâmetros mais antigos na classificação e seleção de mudas (PARVIAINEN, 1981) e, ainda, continua apresentando contribuição importante, podendo ser indicada como parâmetro para essa avaliação. Para Santos et al. (2000), o crescimento em altura de mudas de Cryptomeria japonica está diretamente relacionado com o volume

R. Árvore, Viçosa-MG, v.34, n.2, p.223-232, 2010 
do tubete, estando também relacionado em mudas de Eucalyptus grandis, produzidas em tubetes de plástico rígido (GOMES et al., 2003).

As dimensões dos recipientes e os consequentes volumes influenciam a disponibilidade de nutrientes e água, devendo ser ressaltado que maior volume promove a arquitetura do sistema radicular, à semelhança de mudas provenientes de semeadura direta no campo, apesar de as grandes dimensões provocarem gastos desnecessários, aumentando a área do viveiro, os custos de transporte e a distribuição das mudas no campo (CARNEIRO, 1995) e também acarretando, em geral, maiores custos de produção (GONZALEZ, 1988; GOMES et al., 1990) e de plantio.

Serrano et al. (2006), testando o sistema de blocos prensados em limoeiro 'Cravo' com fertilizantes de liberação controlada, observaram que as mudas de sistema de blocos prensados apresentaram as maiores médias de altura e número de folhas. Segundo esses autores, o maior volume do substrato permitiu maior desenvolvimento das raízes, possibilitando maior exploração e absorção de nutrientes, favorecendo, assim, maior crescimento da parte aérea, o que concorda com os dados apresentados neste ensaio, em que em geral o maior volume do recipiente proporcionou maiores valores às variáveis avaliadas referentes à parte aérea (altura das plantas, diâmetro do coleto, número de folhas, massa seca da parte aérea) e também à massa seca total. O sistema de blocos prensados também conferiu às mudas de quatro espécies de Eucalyptus spp. (BARROSO et al., 2000b; MORGADO et al., 2000; LELES et al., 2000) e de duas de Pinus spp. (CARNEIRO et al., 1988; NOVAES, 2001) maiores valores de altura e diâmetro do colo, em comparação com as produzidas em tubetes, apresentando maior precocidade para o plantio no campo.

Independentemente do processo de produção de mudas, as deformações radiculares devem ser evitadas para proporcionar maior produtividade e estabilidade às árvores, especialmente em regiões com ventos fortes (SCHMIDT-VOGT, 1984). Neste experimento, a diminuição do volume do recipiente reduziu a massa seca do sistema radicular, o que de acordo com Novaes (2001) acontece devido, principalmente, ao fato de os tubetes com menores volumes de substrato limitarem o crescimento e número de radicelas que potencialmente influenciam na absorção de nutrientes e, consequentemente, levam a uma diminuição da massa seca do sistema radicular. O mesmo foi observado por Gomes et al. (2003), em que as médias de matéria seca total das mudas de Eucalyptus grandis em diferentes tamanhos de tubetes e fertilização NPK, independentemente das idades e das fertilizações, foram significativamente superiores à medida que aumentou o volume dos tubetes, semelhantemente aos resultados reportados neste ensaio.

Resultados semelhantes foram observados quando se analisou o crescimento em altura, concordando também com outros resultados de pesquisa, cujos fatores que influenciaram o crescimento em altura de mudas de Pinus taeda atuaram sobre o peso de matéria seca (CARNEIRO, 1981). Gomes et al. (1980, 1990), pesquisando mudas de Pinus caribaea var. hondurensis, Tabebuia serratifolia, Copaifera langsdorffii e Piptadenia (Anadenanthera) peregrina, verificaram também que existe relação direta entre o tamanho do recipiente e o ganho em massa seca das mudas, o que corrobora os dados deste estudo e, segundos esses autores, confere melhor qualidade às mudas.

Trabalhando com diferentes volumes de tubetes em Cordia trichotoma e Jacaranda micranta, Malavasi e Malavasi (2003) verificaram que os índices de qualidade das mudas ao final das 10 semanas após a repicagem indicaram para Cordia trichotoma similaridade entre as mudas conduzidas em tubetes de 120,180 e 300 $\mathrm{cm}^{3}$, enquanto nas mudas de Jacaranda micranta houve similaridade apenas naquelas oriundas de tubetes com volumes de 180 e $300 \mathrm{~cm}^{3}$. Os referidos autores ainda mencionaram que, independentemente do período de avaliação e da variável analisada, as mudas de Jacaranda micranta com as menores médias foram originadas de tubetes de $55 \mathrm{~cm}^{3}$, enquanto as originadas de tubetes de $300 \mathrm{~cm}^{3}$ apresentaram os maiores valores mensurados, concordando com os dados deste ensaio.

\section{CONCLUSÕES}

A altura das plântulas foi beneficiada com o uso do saco plástico e do fertilizante de liberação lenta, sendo o efeito desse incrementado com o aumento do volume do recipiente. Similarmente, observou-se incremento no diâmetro do coleto de plântulas em recipientes maiores. O número de folhas, a massa seca da parte aérea e a massa seca total foram semelhantes nas plântulas sob fertilização com NPK, independentemente do volume do recipiente, o que não ocorreu naquelas sob FLL, em que esse parâmetro diminuiu com o volume do 
recipiente. O cálculo do índice de Dickson 12 semanas após a emergência indicou valores superiores em mudas com a forma de mistura convencional em relação à individual e maior naquelas sob fertilização com NPK, em comparação com aquelas sob FLL.

\section{REFERÊNCIAS}

BARROSO, D. G. et al. Efeitos do recipiente sobre o desempenho pós-plantio de Eucalyptus camaldulensis e E. urophylla. Revista Árvore, v.24, n.3, p.291-296, 2000a.

BARROSO, D. G. et al. Qualidade de mudas de Eucalyptus camaldulensis e E. urophylla produzidas em tubetes e em blocos prensados, com diferentes substratos. Floresta e Ambiente, v.7, n.1, p.238-250, 2000b.

BRISSETTE, J. C. Development and function of the root systems of southern pine nursery stock. In: SOUTHERN NURSERY CONFERENCES, 1991, Biloxi. Anais... New Orleans, 1990. p.67-81.

CARneiro, J. G. A. Produção e controle de qualidade de mudas florestais. Curitiba: UFPR/FUPEF; Campos: UENF, 1995. 451p.

CARNEIRO, J. G. A. et al. Comparison of production methods for containerized pine (Pinus elliotti) seedlings in Southern Brazil.

Metsantutkimuslaitoksen Tiedonantoja, v.302, p.6-24, 1988.

CARNEIRO, J. G. A.; RAMOS, A. Influência da altura aérea, diâmetro de colo e idade de mudas de Pinus taeda sobre a sobrevivência e desenvolvimento após 15 meses e aos seis anos após o plantio. In: SEMINÁRIO DE SEMENTES E VIVEIROS FLORESTAIS, 10., 1981, Curitiba. Anais... Curitiba: FUPEF, 1981. p.91-110.

COLE, J. C.; DOLE, J. M. Temperature and phosphorus source affect phosphorus retention by a pine bark-based container medium.

HortScience, v.32, n.2, p.236-240, 1997.

COX, D. A. Reducing nitrogen leaching losses from containerised nursery plants: the effectiveness of controlled release fertilisers.

Journal of Plant Nutrition, v. 16, p. 533545, 1993.
DAVIDE, A. C. et al. Propagação de espécies florestais. Belo Horizonte : CEMIG, 1995. 41p.

DICKSON, A. et al. Quality appraisal of white spruce and white pine seedling stock in nurseries. Forest Chronicles, v.36, n.1, p.10-13, 1960.

\section{EMPRESA BRASILEIRA DE PESQUISA}

AGROPECUÁRIA - EMBRAPA. Centro Nacional de Pesquisa de Solos. Sistema brasileiro de classificação de solos. Rio de Janeiro: 1999. 412p.

FREITAS, T. A. S. et al. Desempenho radicular de mudas de eucalipto produzidas em diferentes recipientes e substratos. Revista Árvore, v.29, n.6, p.853-861, 2005.

GOMES, J. M. et al. Crescimento de mudas de Eucalyptus grandis em diferentes tamanhos de tubetes e fertilização N P K. Revista Árvore, v.27, n.2, p.113-127, 2003.

GOMES, J. M. et al. Produção de mudas de eucalipto. Inf. Agropec., v. 18, n. 185, p.15-23, 1996.

GOMES, J. M. et al. Influência do tamanho da embalagem plástica na produção de mudas de Ipê (Tabebuia serratifolia) de Copaíba (Copaifera langsdorffii) e de Angico Vermelho (Piptadenia peregrina). Revista Árvore, v.14, n.1, p.26-34, 1990.

GOMES, J. M. et al. Influência do tamanho da embalagem plástica na produção de mudas de Pinus caribaea var. hondurensis. Viçosa, MG: SIF, 1980. p.716 (Boletim Técnico, 9).

GONÇALVES, J. L. et al. Produção de mudas de espécies nativas: substrato, nutrição, sombreamento e fertilização. In: GONÇALVES, J. L. M.; BENEDETTI, V. Nutrição e fertilização florestal. Piracicaba: Instituto de Pesquisa Florestal, 2000. p. 309-350.

GONZALEZ, R. A. et al. Estudio sobre el comportamiento en vivero de Pinus caribaea var. caribaea cultivado en envases de polietileno de 12 dimensiones diferentes. Forestal Baracoa, v. 18, n. 1, p. 39-51, 1988.

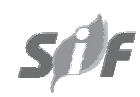

R. Árvore, Viçosa-MG, v.34, n.2, p.223-232, 2010 
HUETT, D. O.; MORRIS, S. C. Fertiliser use efficiency by containerised nursery plants. 3. Effect of heavy leaching and damaged fertiliser prills on plant growth, nutrient uptake, and nutrient loss. Australian Journal of Agriculture Research, v. 50, n. 2, p. 217-222, 1999.

LELES, P. S. S. et al. Qualidade de mudas de Eucalyptus spp. produzidas em blocos prensados e em tubetes. Revista Árvore, v.24, n.1, p.13-20, 2000.

MALAVASI, U. C.; MALAVASI, M. M. Efeito do tubete no crescimento inicial de Cordia trichotoma (Vell.) Arrab. ex steud e Jacaranda micranta Cham. Revista Ciências Exatas e Naturais, v.5, n.2, p.999-1006, 2003.

MATTOS JUNIOR, D. et al. Perdas por volatilização do nitrogênio fertilizante aplicado em pomares de citros. Laranja, v.23, n.1, p.263-270, 2002.

MORAES NETO, S. P. et al. Produção de mudas de espécies arbóreas nativas com combinações de adubos de liberação controlada e prontamente solúveis. Revista Árvore, v.27, n.6, p.779-789, 2003a.

MORAES NETO, S. P. et al. Fertilização de mudas de espécies arbóreas nativas e exóticas. Revista Árvore, v.27, n.2, p.129-137, 2003 b.

MORGADO, I. F. et al. Nova metodologia de produção de mudas de Eucalyptus grandis W. Hill ex Maiden utilizando resíduos prensados como substrato. Revista Árvore, v.24, n.1, p.27-33, 2000.

NOVAES, A. B. et al. Desempenho de mudas de Pinus taeda produzidas em raiz nua e em dois tipos de recipientes, 24 meses após o plantio. Floresta, v.31, n.1, p.62-71, 2001.

PARVIAINEN, I. V.; TERVO, L. A. New approach for production of containerized coniferous seedlings using peat sheets coupled with root pruning. Forestry Supplement, v.62, p.87-94, 1989.

R. Árvore, Viçosa-MG, v.34, n.2, p.223-232, 2010
PARVIAINEN, J. O. Qualidade e avaliação de qualidade de mudas florestais. In: SEMINÁRIO DE SEMENTES E VIVEIROS FLORESTAIS, 1981, Curitiba. Anais... Curitiba: FUPEF, 1981. v.2. p.59-90.

PERIN, J. R. et al. Efeitos de substratos e doses de fertilizante de liberação lenta no teor de clorofila e desenvolvimento vegetativo do limoeiro 'Cravo' em tubetes. Revista Laranja, v.20. n.2, p.457-462, 1999.

PEZZUTTI, R. V. et al. Crescimento de mudas de Eucalyptus globulus em resposta a fertilização. Ciência Florestal, v.9, n.2, p.117-125, 1999.

REZENDE, J. O. et al. Citricultura nos solos coesos dos tabuleiros costeiros: análise e sugestões. Salvador: SEAGRI/SPA, 2002. 97p. (Série Estudos agrícolas; 3 ).

SANTOS, C. B. et al. Efeito do volume de tubetes e tipos de substrato na qualidade de mudas de Cryptomeria japonica (L.F.) D.Don. Ciência Florestal, v.10, n.2, p.1-15, 2000.

SCHMIDT-VOGT, H. Morpho-phisiological quality of forest tree seedlings: the present international status of research. In: SIMPÓSIO

INTERNACIONAL: MÉTODOS DE PRODUÇÃO E CONTROLE DE QUALIDADE DE SEMENTES E MUDAS FLORESTAIS, 1984, Curitiba. Anais... Curitiba: UFPR/IUFRO, 1984. p.366-378.

SERRANO, L. A. L. Sistema de blocos prensados e doses de adubo de liberação lenta na formação de porta-enxerto cítrico. Ciência Rural, v.36, n.2, p.441-447, 2006.

TRENKEL, M. E. Improving fertilizer use efficiency: controlled-release and stabilized fertilizers in agriculture. Paris: International Fertilizer Industry Association, 1997. 151p.

YAGÜE, J. L. F. El suelo y los

fertilizantes. Madri: Ministerio de Agricultura, Pesca y Alimentacion. Instituto Nacional de Reforma y Desarrollo Agrario, 1994. 327p. 